\title{
Storage of Legacy Print Collections: The Views of Australasian University Librarians
}

\author{
PAUL GENONI \\ Curtin University, Perth, Western Australia
}

This paper reports on the results of a qualitative survey conducted with seven managers of university libraries from Australia and New Zealand. The purpose of the survey was to explore both library responses to, and librarians' attitudes towards, issues related to the long-term storage and management of legacy print collections. There is a focus on issues related to future planning for print storage, including the prospects for collaborative storage; the balance between on-site and off-site storage; the impact of mass-digitisation programs; and the desirability of collaboration outside the university library sector.

KEYWORDS Legacy print collections, storage, print repositories, university librarians, massdigitisation, cross-sectoral collaboration 


\section{INTRODUCTION}

Recent years have witnessed increased interest in the long-term storage of print collections. This interest has been driven by the realisation that the traditional paradigm based on the widespread duplication of items intended for long-term storage is becoming unsustainable. The compounding cost of indefinite storage of growing collections; the emergence of digital content that duplicates a significant proportion of the print corpus; the demand for new uses for existing library space; and the reluctance of institutions to fund new building programs, are all factors requiring libraries to reconsider their options for the storage of low use print materials.

Libraries have implemented a number of solutions in order to address the need for forms of print storage that are more effective in terms of space, cost and service. These solutions have included achieving higher densities through the use of facilities such as compactus storage or closed-access stores, and have frequently relied upon the reduced capital and servicing costs required by remote secondary storage sites. The trade off for these savings have come in the form of reduced access; inadequate support in the form of efficient discovery and delivery; and sometimes lower standards of preservation.

At best, these solutions have provided temporary respite. Collections have continued to grow and libraries remain burdened by the substantial costs associated with storing material of rapidly reducing research and teaching value, much of which is widely duplicated. Not surprisingly, managers have become increasingly eager to find a more sustainable approach to print storage, which has in turn led to growing interest in the advantages offered by collaborative or shared print repositories. The arguments supporting collaboration are based on the benefits to a library system that flow from aggregating the storage of legacy print collections in a last-copy repository, with ownership of stored items possibly transferred to the independently managed repository (O’Connor 2004; Payne 2007; Malpas 2009). These benefits include reduced costs achieved by optimising de-duplication across the system; the creation of efficiencies in the discovery and delivery of low-use items, and allowing individual libraries to devote resources to higher-demand collections and services.

Previous research and discussion indicates the international interest in collaborative solutions to the storage of legacy print collections. There have been contributions from the United States (Chepesiuk and Weeks 2002; Reilly 2003; Payne 2005; Seaman 2005; Payne 2007; Malpas 2009); Canada (Gherman 2007; Maskell, Soutter and Oldenburg 2010); the United Kingdom (Sharp 2009); Scotland (Nicholson 2004); Norway (Henden 2005); Europe 
generally (Vattulainen 2004); Korea (Yoon and Oh 2008); and Australia (Genoni 2008; O’Connor and Jilovsky 2008; Genoni and Varga 2009).

This paper reports on the results of a qualitative survey of Australian and New Zealand university library managers undertaken to investigate the respondents' attitudes and opinions that are driving their current decision making with respect to the storage of legacy print collections. The qualitative data reported in this paper supplements quantitative data collected in a 2007 survey that investigated the disposal and storage policies and practices of Australian university libraries (Genoni 2008). The previous survey collected responses from thirty of Australia's forty university libraries. The data pointed to the severe shortage of storage space being experienced by many of the libraries. The results also indicated the increasing use of discarding items as a means of coping with space shortages, including that some libraries had enacted policies of "steady-state" collections whereby all new additions were matched by corresponding discards. Many of the participating libraries were using storage facilities to manage space problems, with twenty (66.6\%) reporting they have access to a storage facility. Fourteen reported having an autonomously owned local store, and shared storage facilities were also reported by eight of the libraries.

The results also indicated uncertainty with regard to the future need for on-site print storage space, with exactly one-third of respondents each indicating a predicted increase; a predicted decrease; and having no opinion on the matter. It was speculated that this ambivalence may be in part a reflection of the unresolved issues and prospects with regard to digitisation, be it the prospects for localised digital collections or the emergence of massdigitisation programs. It was also suggested that the responses and uncertainty may also reflect each library's own economic and political realities in terms of obtaining funding for expanded storage facilities.

\section{BACKGROUND}

Storage of print material has been an issue for Australia's university libraries for some years, and discussions regarding the possible development of collaborative storage-possibly on a national basis-have continued intermittently since the late 1990s (Genoni 2007). Many of the responses to storage pressures to date have been piecemeal, based around local and temporary solutions, and with limited cooperation between libraries.

There have been two exceptions, however, which are indicative of both the potential for, and the limits to, collaborative storage in Australia. Australia's foremost print store is the 
CARM (CAVAL Archive and Research Materials) Centre. The CARM Centre is managed by CAVAL, a consortium owned by eleven Australian universities, and has been offering a service to members since 1997. The original vision for the CARM Centre was to build an independently managed last copy repository (the “CARM Collection”) that would encourage de-duplication of the collections of member libraries. This has been the outcome to some extent, but the practice of many members has been to lease space within the CARM Centre and use it for the storage of material of which they retain ownership. The attempt to create the CARM Centre as a last copy repository has therefore receded in favour of a jointly-owned owned store. While the CARM Centre is located in metropolitan Melbourne, and the current membership is dominated by universities from the state of Victoria, universities from other states have recently joined the consortium with a view to gaining access to the storage service. These include the Universities of New South Wales, Western Sydney and Tasmania.

The second major facility is the University Research Repository South Australia (URRSA), a jointly owned store providing for the needs of three South Australian universities. Once again, however, the URSSA operates on a model of retained ownership of stored material, rather than ownership being ceded in order to create a collaboratively owned last copy repository.

Two recent developments in storage for Australian university libraries indicate the pressures they are under to adapt their storage services. Firstly, in December 2010 CAVAL officially opened an extension to the CARM Centre. The extension, referred to as CARM2, increases the capacity of the facility from 1 million volumes to in excess of 3 million volumes. The A $\$ 14$ million cost of CARM2 has been largely met by three CAVAL members, Monash University, the University of Melbourne and RMIT University, in order to acquire sufficient storage space for legacy print materials to allow for up to thirty years of collection growth. Once again, however, the expansion model relies on the two libraries acquiring space for storing their own material of which they retain ownership.

Secondly, Macquarie University in Sydney opened a new A\$94 million library in August 2011. Integral to the new facility is the installation of an Automated Storage and Retrieval System (ASRS). While this form of advanced high-density storage is well established in the United States (for example; California State University, Northridge and Long Beach; Chicago State University; University of Chicago) and elsewhere (University of British Columbia, Canada), this is the first to be installed by an Australian university library. The ASRS can cater for the storage of approximately 80 per cent of the Macquarie Library's print collection of approximately 1.8 million volumes. 
These developments at the CARM Centre and Macquarie University broadly indicate the choice that is available to Australian university libraries in terms of dealing with print storage either through an existing cooperatively owned store or continuing to deal with the issue autonomously. They also raise important issues about both the long term storage and management of Australia's legacy print collections, and the limits of university library collaboration in the Australian context.

\section{METHODOLOGY}

An invitation to participate was sent to twelve Australian and New Zealand university librarians in June 2009 (Appendix A). All correspondence with participants, including the distribution and return of the surveys, was conducted by email. Recipients were provided with background about the research including a guide to previous related research.

The research used a structured survey consisting of eleven questions inviting openended responses (Appendix B). Respondents were encouraged to treat the survey as a form of interview and to provide discursive answers.

The sample of university librarians invited to complete the survey was chosen purposively in order to select for the following:

1. Representatives from different 'types' of universities. This includes representation from the established research intensive universities (referred to in Australia as the Group of Eight or Go8), plus representation from other identifiable categories of universities that have a variable mix of teaching and research. Three of the responses came from librarians managing Go8 libraries (Nos 2, 5 and 7), and one from a similar New Zealand library (No 3).

2. A focus on libraries from the state of Victoria. As the survey was in part exploring the prospects for collaborative storage, it was believed that Victorian librarians, managing collections within proximity of the CARM Centre, would be well placed to reflect on the influence of this facility on their own storage choices. Five of the responses were from Victorian university librarians (1, 4, 5, 6 and 7), one from elsewhere in Australia (2), and one from New Zealand (3).

Recipients of the survey were given the following definition of the term "legacy print collections”, as the phrase was used in several questions. 
The term "legacy print collections" ... refers to the collections of print items that are in very low circulation or demand but which may nonetheless retain some research value. The term includes both serial and non-serial publications.

Seven surveys were completed and returned between July and October 2009. All five non-responding librarians were managing non-Victorian universities, and non-Victorian libraries are therefore underrepresented in the results. Two non-respondents were from Go8 libraries, and three from other libraries.

In accordance with an undertaking all obviously identifying information has been deleted from this report, and each respondent is referred to by a number.

\section{SURVEY RESPONSES}

The survey was divided into two parts. Part A consisted of four questions asking participants to report on “your library's storage of print materials”. Part B consisted of seven questions asking participants to provide "your personal views regarding the future storage of print collections and factors that might influence the storage of legacy print collections”. As the purpose of this paper is to report the participants' personal views on storage issues the focus is on responses to the Part $\mathrm{B}$ questions.

It is relevant to note, however, that responses to Part A questions confirmed the findings from the previous quantitative survey regarding the shortage of storage space. Five of the seven libraries represented are actively acquiring additional remote storage as part of their short-to-medium term planning, and for several libraries there is an air of urgency regarding their planning for additional space. Not only are primary library sites effectively full, but stores are also reaching capacity. Respondents also reported that the problems with print storage are longstanding and libraries are looking to find more permanent solutions.

In describing the factors that are driving their library's storage decisions respondents mentioned the key factors of increased digital content; decreased use (including borrowing) of parts of collections; demand for other uses of primary library-sites; and the difficulty in obtaining new on-campus storage space.

\section{COLLABORATION}

A key question in Part A asked respondents to indicate if "your library [has] a preference for independent or joint/collaborative print storage?” Responses indicate that there is a strong preference for joint or collaborative storage, but that the issue is far from straightforward. 
One respondent provided a concise account of the benefits that are typically claimed for collaborative storage solutions.

... we would prefer joint storage, as it allows collection de-duplication, access to expensive facilities such as high speed digitizers, and should have lower operating costs as retrieval and building maintenance costs would be shared. (1)

This respondent also indicated, however, that the economic benefits might not be the case for all libraries.

This viewpoint is predicated on the assumption that it is more economical to operate such a facility in conjunction with others. Naturally, this must be tested on a case by case basis. (1)

Other responses to this question also pointed to cost as a determining factor. The evidence collected by at least one of these libraries (which currently use "both independent and collaborative storage as part of our strategy”) favouring the use of collaborative facilities, while also noting that storing low-use material was a specialised service that could benefit from outsourcing.

\begin{abstract}
A key determinant in our participation in the CARM2 store was a sense that we wanted to outsource our largest store to an organisation where storage was their core capability. ... We are also getting the most affordable solution via CARM2. For example we are fitting out [our own] smaller capacity store for about the same cost as our CARM2 store ... Our University Property and Campus Services investigated the market and all costs as part of the decision making process to proceed with CARM2. (5)
\end{abstract}

This respondent also noted, however, that any arrangements entered into now may not necessarily be sustainable, but rather interim solutions that will "buy time" pending future developments.

It all depends on resources and how high a standard that your academics demand for collections. This [CARM2 expansion] is coming at considerable cost and may 
not be sustained into the long term, but at least in the next 30 years of our lease at CARM2 plus the store we have bought ourselves a good buffer! (5)

Other respondents also indicated that their library is being driven by cost factors to consider remote collaborative storage, and are receptive to the concept provided delivery services are adequately supported.

While on site storage has been a preference, there is now active consideration of collaborative off-site storage . . . Off site is not seen as an issue as long as there are appropriate request and delivery services in place including 24 hour turnaround ... Space and cost are the major reasons why independent, on site storage is a limited option over and above what already exists. (6)

The issue of collaboration at a national level was also raised in several responses. One respondent noted the increasing support-including amongst the research community—for the development of a national repository based on a last-copy principle.

The Library does not have a formally stated position on independent or shared storage. However the notion of a national shared store with a single copy for permanent retention has long been an attractive solution that appears to be gaining strength and acceptance in a wider circle including academic staff. (3)

As was pointed out by another respondent, however, remote shared storage does not necessarily imply collaboration to the point where ownership of last copies is ceded. This respondent noted the benefits associated with outsourcing storage, but argued for a shared storage facility based on retained ownership as opposed to a repository based on ceded ownership.

[The Library] has a preference for collaborative storage arrangements. It does not wish to manage extensive stores that require daily servicing, as is the case with library stores. It is also not interested in joint stores, such as the type ... whereby member institutions cede ownership of their material. The Library wishes to retain ownership of its own material, for accounting, collection management and reputation reasons. Accounting reasons include the fact that written off stock disadvantages the University's bottom line. Collection management reasons 
include flexibility regarding what is kept and where it is kept, including the ability to return material to a campus library as use demands. Reputation reasons include the fact that size of library collections is frequently a factor in university ranking schemes. (7)

As noted the respondents to the survey were largely drawn from Victoria and therefore have local access to the existing CARM Centre. A respondent from a non-Victorian based university noted that the library had a "preference for independent, local storage", while also pointing out that, "Local collaborative storage has been discussed but not pursued, largely on account of the differences in institutional requirements”. (2)

\section{PART B}

Part B of the questionnaire asked respondents to address questions by providing their "personal views".

\section{FUTURE QUANTUM OF ON-SITE STORAGE}

The first question in Part B asked the library managers if they "believe academic libraries will require more or less on-site print storage space in the future?" Several were quite adamant that less space for on-site storage will be required. For these respondents the key factors are the decreasing reliance on print materials and the growing demand for other uses of library space.

Less storage will be required - there is an increasing call for student space, and a decreasing level of use of print material. (1)

There has been a major program across the sector to re-visualise and redevelop library spaces and I think that this is what is driving many decisions related to storage and retrieval. These initiatives are resulting in reduced collection spaces and/or the transfer of print collections to non public spaces with access provided through request and delivery or other means. (6)

. . l libraries have been transformed over recent years to convert them into learning spaces ... This generally entails relegating legacy collections to off-site 
storage. On balance, collections will comprise a smaller percentage of on-site space in the future. (7)

For another respondent the matter of less on-site space was associated with the growing confidence in the capacity for reliable delivery from off-site.

Less. Academics who once thought that they needed everything to hand on the open shelves have been impressed by good delivery systems from off-site stores.

Other respondents, however, were less certain about the shift to off-site storage, or argued that more on-site space will be needed on the basis that print acquisitions will continue to be substantial.

I do not believe that academic research will reach the point in the foreseeable (at least to me) future when they are able to discard as much material as they take in, and that therefore more space in total will be required. Where suitable, convenient and affordable off-site storage is available it is likely that libraries will be able to manage without increases to the on-site collection space. (2)

We will continue to require more on-site storage into the immediate future. [We have] 67,500 serials the majority of which is electronic through our big deals. We still continue to buy paper monographs. We have not bought as many e-books as the newer universities. I have also observed exponential growth in the use of ebooks in some universities that is unsustainable and some have had to turn them off towards the end of the year as budgets have been overspent. (5)

It is notable that both of these responses came from Librarians of two of the larger, and more established research libraries. As a respondent from a less research focussed university noted, "I think that this [future demand for on-site storage space] will vary according to individual collection development and access policy" (6). Certainly it is the research intensive universities and libraries that are likely to be reluctant to move more material offsite than is necessary, whereas redundant teaching collections will inevitably have a higher percentage of material suitable for relegation to an off-site store or permanent withdrawal. 


\section{FUTURE QUANTUM OF OFF-SITE STORAGE}

The library managers were also asked to discuss whether they believe that academic libraries "will require more or less off-site print storage space in the future?” The common-although frequently qualified-response is that academic libraries will require additional off-site storage capacity. Typical responses included the following:

More. Our library has just prepared a paper that has forecast needs for print collections for the next 10 years. It allowed for weeding and reduced acquisition of print because electronic formats are available, and the space required is still significant. As space is at a premium on the University's campuses, anything additional that the Library might obtain will almost certainly be off-site storage. (3)

I do not believe that academic research will reach the point in the foreseeable future when they are able to discard as much material as they take in, and that therefore more space in total will be required. For this reason . . . there will be a greater demand for off-site storage from those libraries for which retention of their print collections is a priority. (2)

More storage will be required - a combination of the on-site issues, and a slow (or non-existent) migration of print monographs to digital media will mean more material must be stored off-site. I believe researchers will still want these materials - just not right here, right now. I believe there will be a sudden tipping point at some stage, where a majority of short run, academic printing will migrate to digital format and print on demand. ... If I had to guess [when this will occur] I would say somewhere between 2015 and 2020. (1)

A similar view was provided by another respondent who simply replied that the need will be for “More in short term but may need less in the longer term”. (4)

Several of the library managers noted, however, that the extent to which more off-site storage is required will again be a function of the type of library and the nature of its collection. 
Libraries of research-intensive universities will have an ongoing requirement for off-site storage, although the rate of growth has slowed down. There may be attempts to cooperatively rationalise journal collections where material is also available electronically, however institutional factors have limited this activity in the past and will continue to do so into the future. (7)

Two responses from managers of research-intensive libraries acknowledged that their circumstances were different from those with collections based on teaching and learning needs.

There will be some academic libraries for which long-term access to legacy collections is not necessary due to the academic profile of the university. For these storage, whether on-site or off-site will not be a priority. (2)

At this point in time I suspect we will continue to require more off-site storage into the future. This is influenced by [our] specific needs. I know that there is market intelligence that there is an increasing need for off-site stage into the future. However I know from personal experience at newer universities that they will continue to make do with onsite spaces and continue to rely heavily (and increasingly) on electronic resources and discarding of lesser used materials. (5)

\section{IMPACT OF MASS-DIGITISATION}

One factor that is likely to influence the future storage decisions of some libraries is the emergence of mass-digitisation programs based on the collections of the world's leading libraries. Participants were therefore asked for their opinion regarding, "In what way do you believe mass-digitisation programs (for example, Google Books) will impact upon future print storage requirements?”

While one respondent-from a non-research intensive university-provided an unequivocal claim that mass digitisation "Will provide significant benefits in reducing storage needs and improving access” (4), other responses were more circumspect. For while respondents acknowledged that mass-digitisation was an important development, the opinion was expressed that many research items would still escape digitisation, or that it would not 
replace the need for researchers to have access to the original printed item. For one such respondent it was intrinsic to the nature of research library collections that they included unique-or near-unique-items.

Mass digitisation will make a significant difference in the future but until that plays out we will continue to rely heavily on print collections, particularly for research higher degree students, academics and scholars. We still have extensive scholarly collections that are rare. Sometimes digitised versions become available but they are not always the same editions as the ones we hold. We would never discard these special collections that set our university apart from the rest of the sector. We have strategic advantage through the ability to offer primary sources to our university community. . . . They are now vital in exposing undergrads to new horizons and enticing students into post-grad research. (5)

Another argument for retention of scholarly monographs was based on the style of readership these books required, which made them more amenable to print.

At the moment I see these more as useful (to some) adjuncts to the print collections rather than eliminating, or even seriously impacting on, the storage requirements for books. Where digital access can have the most impact on storage requirements is with journals, not books. And I think, too, that there is something about the mode of discourse of the academic monograph (as opposed to a textbook ...) which involves the development of an extended argument and careful attention. The greater the proportion of reference and textbook material the greater is the potential impact on print storage requirements. (2)

This concluding acknowledgement of the different circumstances of non-research intensive collections was echoed by the manager of a non-research intensive library.

I think for less research intensive universities where the retention of as much material as possible for future research use may be less of a collection development imperative, mass digitisation projects will impact to the extent that they become one more factor for consideration when reviewing material for retention or discard ... The reliability of access and sustainability of e-storage 
will continue to be a consideration when making decisions about future print storage requirements. (6)

Other participants provided cautious responses to mass-digitisation based on a lack of confidence in the business model underpinning these programs and continuing uncertainty about the copyright implications.

It is too early to say. Google-for example-is not a collecting institution, and it is impossible to say whether or not its interest in scholarly communication will be sustained and/or affordable. I'm a sceptic. I think that, for budgetary reasons, research libraries may decide to store less, but the mass-digitisation era may have as little impact on storage needs as the transfer to electronic resources has had to date. (7)

I have seen no pricing for this product. I believe copyright challenges will tie up any truly accessible mass digitisation project. (1)

Mass digitisation projects will have an impact in the future. This will depend on the access that Google Books will provide and the associated cost. I doubt however that academics are ready to hand the library over to Google. (3)

\section{NATIONAL AUTONOMY}

Some of the previous planning for the long term retention of research materials in Australia and New Zealand has been based on a belief that they should be independent with regard to their information needs. In order to investigate whether this thinking was still influential in the era of globalised information supply participants were asked if they, "believe it is necessary for Australia (or New Zealand) to be as independent as possible with regard to its research library needs?”

There was evidence in responses that the "doomsday" scenario that has underpinned thinking in this regard is still influential.

It is important that the University community can get ready access to the research information that it needs. At the moment, that is provided by local ownership 
supplemented by inter-library loan. Until other models can provide a satisfactory and cost-effective service that is as good, libraries are likely to remain relatively independent. There is the "just in case" argument—just in case there is a global catastrophe and the internet is no longer available-which seems low risk but very high impact. If a science fiction fantasy were realised, then one would like to think that a repository of knowledge was available to start rebuilding. (3)

Other respondents acknowledged the issue of crisis-based risk, but suggested that it had been overtaken by advances in storage and transfer technologies.

From a risk mitigation perspective it could be argued that independent approaches within countries/regions is desirable, however I think that advances in digital technology and storage will influence and change approaches to retention of research collections. (6)

Portico, JSTOR and CLOKSS are important international initiatives. If there is a crisis of such proportions that Australia does not have access to material held in these stores we probably won't be in a position to want access. There is a practical last copy rationale within Australia, because it may be cheaper and easier to consult or transmit material within the country, otherwise I do not think it is an issue. (7)

It was argued that the time for true autonomy has past, and although it might remain (to some extent) desirable, it has become an unrealistic goal.

No. It can't possibly be. That's not to say that there may not be some subjects or areas where this is entirely appropriate. If we were to think about the material which we do not possess rather than the material we do possess and are anxious to retain access to, we would realise how dependent we are on the holdings of other countries. (2)

For other respondents a case for national autonomy can still be made in terms that echo the call for the nation to be independent in its information needs. 
We should try to hold as much print material which we can sensibly support. We will always have some reliance on overseas suppliers, but we should try to minimize this exposure. (1)

In other cases, however, the desire for autonomy is based on the belief that particular libraries should aspire to the prestige associated with independence.

Yes. This will not always be affordable for some but if the sector wants to be internationally competitive, we will need world class collections onshore. Mass commoditization of education will mean that some players will not own extensive local collections and rely on other sources. But elite universities . . . will always value cultural collections and historical materials as long as they contribute to the prestige of the university and our rankings and international standing. (5)

\section{NATIONAL v INTERNATIONAL CONTENT}

The matter of national interest was pursued further in a question whereby participants were asked how they "perceive the differences with regard to the academic library sector's obligations to the permanent retention of Australian publications as opposed to international publications?” The purpose of this question was to determine if respondents believe that future print storage should prioritise the retention of material of Australian origin, or in other ways related to Australia.

The majority response indicated that while there may be some responsibility for universities in this regard, it was primarily a task for the national and state libraries that are mandated to acquire material of national origin or interest under the terms of legal deposit legislation.

I see the retention of Australian publications as primarily the responsibility of those libraries which enjoy copyright privileges. However research library collections can be important adjuncts to the these collections, and can provide significant value. (2) 
With regard to published material, I think academic library obligations to Australian material are minimal ... The national and state libraries are in a different position, and do have a greater obligation to retain published Australian material. (7)

Nonetheless, as one respondent noted, "librarians accept a natural responsibility for collecting and preserving their own literature" (3), and several pointed to particular categories of national material for which university libraries need to be responsible-some of which may not be duplicated in the collections of deposit libraries.

With regard to manuscript or unique material, both academic and national/state libraries have a responsibility to retain Australian material they accept into their collections. This also applies to unique born-digital material. (7)

I do not see this as an academic library obligation, with the two exceptions: products of that particular University-particularly the University Press, and research outputs. Material needed by that particular University for study, teaching and research and other Australian content should be managed by the relevant State and National Libraries. (1)

Indeed most responses to this question noted that in practical terms the comprehensive collection and retention of Australian content was not ensured by the deposit requirements, and therefore cross-sectoral collaboration is needed to ensure this goal is achieved.

We will seek to maintain and extend our Australiana collections in areas of academic excellence ... However we can also rely on state and national library holdings in addition to the heritage materials held by other University libraries and archives. (5)

[There is] greater responsibility for Australian material but it can be addressed collaboratively. (4)

I think that there is a strong responsibility for the academic library sector to ensure the preservation and retention of Australian publications (in conjunction 
with the State and National libraries). There does need to be a national collaborative approach to this which is happening to some extent but still lacks some coherence. (6)

\section{CROSS-SECTORAL COLLABORATION}

Access to shared storage in Australia has largely been confined to the academic library sector. Recently there has been a case put for a more inclusive approach to the management of the national research collection (Stephens 2009), and National and State Libraries Australasia (NSLA) has been considering a "distributed repository" model as part of a reappraisal of their cooperative arrangements (NSLA 2010). In order to explore attitudes towards broadening access to collaborative storage participants were asked, “To what extent do you believe cross-sectoral collaboration (for example, academic libraries collaborating with government and/or state libraries) is desirable and/or possible for long term storage of legacy print collections?” Several respondents expressed enthusiasm for the concept of collaborative, cross-sectoral storage.

Academic staff recently indicated that they no longer consider that ownership of material is important but they want confidence in the Library's ability to provide access. A shared store would meet this need . . . The concept of a legacy collection of single copies held in a shared repository on behalf of a wider group, either sectoral, regional or national, remains very attractive as a solution to the problem of burgeoning print collections. (3)

A national strategy is critical, [with] collaboration between the National Library, the state libraries, and the leading research university libraries” (2)

This second respondent was also quick to point out some of the political issues that might be entailed in achieving collaboration across sectors.

Unfortunately I don't see any evidence of either the good-will or the commitment on the part of the academic library community in general, and of the research libraries in particular. More's the pity. (2) 
Another in-principle supporter of the concept also noted the difficulty in obtaining cross-sectoral collaboration, with mention of a recent example where cross-sectoral collaboration had failed. To this respondent, however, the challenges to collaboration are indicative of a practical gulf that separates library sectors rather than any lack of collaborative spirit.

While this collaboration is desirable it appears to be beyond the realms of reality. A strong partnership between the State Library of Victoria and Victorian academic libraries was split asunder when the State Library withdrew (although on a personal level the relationships remain healthy) for budget reasons. I believe that there is probably insufficient commonality of purpose for these relationships to flourish. (1)

This was another issue that also indicated the differences within the university library sector. One of the Go8 librarians pointed to a difference of practice not only between university libraries and other sectors, but also between libraries serving different types of universities, as a cause of a lack of "trust" that would be needed to underpin collaboration.

We have considered involvement in last copy schemes across the whole country but Go8 libraries are unable to trust non-Go8 universities, let alone government and other special libraries for long term reliability in holdings. My personal view is that universities value their libraries more than other sectors. The closure and decline in libraries outside universities in recent years does not give me confidence in relying on other sectors. Collaborative storage appears to work better on a geographical rather than sectoral basis. (5)

Other respondents also raised doubts about the value of cross-sectoral collaborative storage, noting in particular the uncertain benefits that it would produce in terms of deduplication.

I think it is unlikely that any significant collection rationalisation will occur as a result of cross-sectoral collaboration, above and beyond what already occurs. It is also evident that it is easier and cheaper to store material than to manage extensive de-duplication programs. (7) 
May be useful but overlap in collections may not be great so sectoral collaboration will deliver better results. (4)

\section{DISCUSSION}

On the basis of their responses it is evident that the university librarians surveyed are concerned about issues relating to print storage, and as managers they will seek cheaper and more space-efficient options for the storage of print collections. They are, however, generally uncertain about a number of the factors that will influence their decision making with regard to storage strategies.

It is apparent that many of their personal attitudes and opinions with regard to print storage are viewed —not unexpectedly — through the lens of their own library. Respondents referred frequently to a number of critical "local” factors that influence their opinions and capacity to make storage decisions. These include:

- The research profile of their university (and library) and its commitment to supporting research as opposed to teaching and learning.

- The economic circumstances of a university.

- The legacy of previous decision making with regard to library buildings and storage that have bequeathed existing storage conditions.

- The geographic location of their university and therefore the degree to which it has ready access to existing joint storage.

In each case these local circumstances are beyond (or almost beyond) the influence of the libraries or librarians concerned, and they will be subject to slow change rather than rapid transformation. In other words library managers-irrespective of their personal views and preferences-are often working with constrained choices when it comes to storage issues. The opportunity for transformational change to print storage, such as that being undertaken at Macquarie University with installation of a substantial ASRS, is an exception in Australia.

In addition to the local conditions that are intrinsic to a library's storage options, university libraries are also constrained by the national higher education systems and networks. In Australian terms this means a system whereby universities are subjected to a considerable degree of Federal Government regulation and control, including the use of various financial incentives and rewards upon which universities are dependent for both operating revenue and material expansion. There is an ongoing negotiation between 
Government and universities in order to set priorities, some of which are eventually identified for "research infrastructure" funding. While at times the Council of Australian University Librarians (CAUL) has been active in promoting print storage as a candidate for infrastructure funding, the issue has not received the sustained support or emphasis from the CAUL membership needed for success (Genoni 2007). Print storage and rationalisation initiatives depending on national collaboration have been implemented in the United Kingdom - in the form of the United Kingdom Research Reserve (UKRR)-because the issue received sustained support from within the research library community which in turn led to designated Government funding (Wright and Crawford 2008). In addition the sole New Zealand respondent to this survey reported that planning was proceeding on a national scale, noting that "New Zealand university libraries have received government funding to investigate the feasibility of collaborative solutions to the storage of print collection” (3). In Australia, however, the lack of ongoing CAUL support for a system-wide response to storage problems has meant that libraries need to continue to find solutions that are local and/or draw upon existing infrastructure, and that can be primarily funded from existing university budgets.

Respondents were generally in agreement regarding the advantages and attractiveness of collaborative storage, with responses indicating that as the print corpus is relegated libraries will be looking to collaboration as the key to both the cost-effective and serviceeffective management of this material. However, the key reasons why some Australian university librarians have shied away from fully-committing to collaborative storage initiatives are indicated by the survey responses.

Firstly, for those universities that see their primary mission as teaching and learning there is little incentive to send material to any store, be it local or national. The core needs of these libraries and their users can be met from a "steady state" collection, and there is currently sufficient support from other libraries using existing discovery and delivery services to meet additional needs.

Secondly, for some libraries there is a material advantage is retaining ownership of print material, irrespective of its level of use. The response of one Go8 librarian in particular indicated that this choice is based both on concern about losing the competitive advantage associated with large research-based collections, and the practicalities of accounting practices that favoured retaining ownership. If some major libraries choose to stay outside a last-copy repository for these reasons, then the prospects of winning support for such a repository are severely diminished. 
Thirdly, even with respondents who expressed a desire to find long-term sustainable storage solutions, there is uncertainty regarding exactly what this might entail. This uncertainty is a reflection of the volatile technological environment and the potential for mass digitisation to render long-term storage commitments obsolete for all but the deposit libraries that are legally required to retain print copies. For while several respondents were adamant that collaborative storage is their preferred solution, they also expressed concern about the ongoing system-wide financial commitment in the face of declining need for print. And whereas respondents acknowledged mass-digitisation as an important development, they also stopped short of declaring exactly what impact it would have on print storage. They appear to be taking a "wait and see" approach, unsure about the long-term commitment of Google Books (the only mass-digitisation program specifically mentioned) to supporting scholarly content.

At the same time, however, there are powerful drivers that are in favour of collaborative storage. These are being particularly felt by libraries serving the research intensive universities. It is in these libraries that issues of storage space are most critical, because they remain reluctant to use large-scale disposal (or the "steady state" collection) as a means of managing short-term shortage problems. As one Go8 respondent noted:

Unlike newer universities, [we are] reluctant to dispose of any collections even in the case of paper journals that duplicate online. Similarly while newer universities dispose of lesser used monographs, we are more likely to retain it in off-site stores. The two off-site stores will most likely ensure that on-campus libraries are able to house materials that are used more frequently. . . . [We] are seeking to minimise the discard of potentially important scholarly collections. (5)

In such circumstances remote ("off-site") storage is necessary, and given the scale of the space needed and the cost involved, some form of collaborative storage is preferred. It is notable that respondents did not point to user resistance to remote storage as being an issue. Almost all respondents discussed the changing attitudes of their users at some point, and universally indicated they have come to accept either that access can be provided by means of a digital surrogate, or that delayed access to stored content may be necessary if the original item is required. There was also, however, a recognition that different categories of material require different treatment, with several respondents indicating users are more agreeable to 
the relegation of print journals to storage (where a digital copy is available), rather than monographs.

\section{CONCLUSION: A NATIONAL REPOSITORY for AUSTRALIA?}

As noted in the Background, Australian university libraries have been engaged in a discussion about collaborative storage for over a decade. In this period there has been occasional agreement, some gains, and a great deal of hesitancy in the face of other priorities. Australia is, however, in danger of falling behind international developments, and as a respondent noted, Australian storage management needs "to be aware of, and aligned with, overseas developments” (2).

What is indicated by the survey responses is that while there is some support for collaboration as a principle, this alone is not likely to be sufficient for Australian university librarians to support adoption of a system-wide approach to storage issues. Respondents indicated that their decisions will be driven by the effective management of the collections and services offered by the particular library they manage. It is also the case, however, that the realities of research infrastructure funding in Australia are such that government financial support for a storage facility will only be won if the benefits are demonstrated and argued on a system-wide basis. That is, the Australian Government and the Department of Education, Employment and Workplace Training have a recent record of supporting initiatives that are as collaborative and widely beneficial as possible.

One component of building a successful case for government support of a national (or similar) repository is the need for a sound evidence base. The lack of verified cost-benefit data has long been a problem for managers making storage-related decisions. A number of respondents to the current survey (in addressing Question 3) described the relevant data collection within their own library, but also pointed to the lack of comparable data from across the wider library system that is needed for informed decision making. Several pointed to the need for system-wide data with regard to unique holdings and overlap between collections, with one specifying the lack of detailed data regarding the "cost-benefit" implications of various storage options. This comment included the claim that the scale of this work is a matter for "a coordinated national approach" similar to the approach used in other countries. 
Generally we need to undertake some cost/benefit work on the various options that libraries have open to them. But we also need to see the issues as at the very least ones requiring a coordinated national approach. The UK has attempted this: Australia needs to do the same. (2)

While some of the work needed to assess the potential impact of a national storage system in Australia has commenced (Genoni 2009), clearly much more remains to be achieved.

To be successful, a proposal for government funding would also need to be clear about the extent of the "system" that will benefit. This would require clarity around the scale of the proposed repository, which might feasibly entail either a single national repository facility; or a federated series of regional repositories. The scaling of a proposal would also raise issues around the library sectors to be included, but would again be most likely to be successful if it encompassed all research libraries-including university libraries, the National and state libraries, and the research-focused special libraries. A funding proposal of this type would need to be jointly led by both CAUL and NSLA, to have broad support from other key library bodies, and to have a commitment to inclusiveness.

As several survey responses indicate there are some difficult "politics" involved in gaining the necessary support for broad cross-sectoral collaboration, or indeed winning support from across existing divisions within the university library sector. Without, however, reaching a unified commitment to broadly-based collaboration, Australian research libraries may find themselves doomed to maintaining a system of print storage that is a financial and service drag on both individual libraries and the broad network of research libraries.

\section{REFERENCES}

Chepesiuk , Ron, and David Weeks. 2002. The Harvard Model and the rise of shared storage facilities. Resource Sharing and Information Networks 16(2), 159-168.

Genoni, Paul. 2007. Towards a national print repository for Australia: Where from and where to? Australian Academic \& Research Libraries 38(2): 84-98.

Genoni, Paul. 2008. Current and future print storage for Australian academic libraries: Results of a survey. Library Collections, Acquisitions \& Technical Services 32(1): 31-41.

Genoni, Paul, and Eva Varga. 2009. Assessing the benefits of a national print repository: An Australian overlap study. College \& Research Libraries 70(6): 555-567. 
Gherman, Paul. 2007. The North Atlantic Storage Trust: Maximising space, preserving collections. Portal: Libraries and the Academy 7(3):273-275.

Henden, Johan. 2005. The Norwegian Repository Library. Library Management 26(1/2): 7378.

Malpas, Constance. 2009. The gathering cloud: How shared repositories are transforming the library landscape. Paper presented at the Kuopio-3 Conference, October 29-30, 2009. Available at:

http://www.varastokirjasto.fi/Kuopio3/Malpas.pdf [Accessed December 13 2010]

Maskell, Cathy, Jennifer Soutter, and Kristina Oldenburg. 2010. Collaborative print repositories: A case study of library directors' views. Journal of Academic Librarianship 36(3): 242:249.

National and State Libraries Australasia. 2010. Reimagining Libraries: Project 7: Collaborative Collections Distributed Repository Discussion Paper. Available at: http://www.nsla.org.au/publications/papers/2010/pdf/NSLA.Discussion-Paper-20101220Project.7.Distributed.Repository.Discussion.paper.pdf [Accessed 23 December 2010]

Nicholson, Catherine. 2005. CASS: A collaborative academic store for Scotland. Library Management 26(1/2): 32-41.

O’Connor, Steve. 2004. Collaborative strategies for low-use research materials. Library Collections, Acquisitions \& Technical Services 28( 1): 51-57.

O’Connor, Steve, and Cathie Jilovsky. 2008. Approaches to the storage of low use and last copy research materials. Library Collections, Acquisitions \& Technical Services 32(3/4): 121126.

Payne, Lizanne. 2005. "Depositories and repositories: Changing models of library storage in the USA,” Library Management 26(1/2): 10-17.

Payne, Lizanne. 2007. Library Storage Facilities and the Future of Print Collections in North America. Dublin, Oh: OCLC: 5. Available at http://www.oclc.org/programs/publications/reports/2007-01.pdf. [Accessed 13 December 2010]

Reilly, Bernard F. 2003. Developing Print Repositories: Models for Shared Preservation and Access. Washington, DC: Council on Library and Information Resources: 6. Available at http://www.clir.org/pubs/reports/pub117/pub117.pdf. [Accessed 13 December 2010].

Seaman, Scott. 2005. Collaborative collection management in a high-density storage facility. College and Research Libraries 66(1): 20-27.

Sharp, Steven. 2009. No more room aboard the ark! A UK higher education perspective on space management. Interlending \& Document Supply 37(3): 126-131. 
Stephens, Matthew. 2009. Heritage book collections in Australian libraries: What are they, where are they and why should we care? Australian Library Journal 58(2): 173-189.

Vattulainen, Pentii. 2004. National repository initiatives in Europe. Library Collections, Acquisitions, \& Technical Services 28(2): 39-50.

Wright, Nicola, and Jean Crawford. 2008. Supporting access to the UK's research collection: The UK Research Reserve project. Interlending \& Document Supply 36(4): 210-212.

Yoon, Hee-Yoon, and Sun-Kyung Oh. 2008. Shortage of storage space in Korean libraries: Solutions centering upon hub-based collaborative repositories. Aslib Proceedings 60(3): 265282.

\section{APPENDIX A: INVITATION TO PARTICIPATE}

Dear

I am writing to invite you to participate in an email interview regarding the future storage of print collections by Australian academic and research libraries. These interviews form part of an ongoing research project investigating the prospects for collaborative print storage in Australasia. The research is being undertaken with the support and participation of CAVAL Ltd.

A previous questionnaire, undertaken with the assistance of CAUL in 2007, collected and reported the basic data concerning current print storage and disposal activity. The purpose of the follow-up interview is to collect additional qualitative information about the various drivers that are influencing senior decision makers with regard to the storage of legacy print collections.

University librarians from Australia and New Zealand are being invited to participate. If you agree to participate, the interview-consisting of twelve questions-will be conducted by email. You will be asked to respond within several weeks.

It is the intention to present a report or reports of the interviews in refereed journals and possibly other avenues such as conference presentations. Participants will not be identified by name, but characteristics of the participant's library will necessarily be described or become apparent to readers. By participating in the interview you will be agreeing to having your responses quoted from or referred to in the proposed publications. The research is currently being appraised by the Curtin University Human Research Ethics Committee and will proceed when approval has been granted.

For your interest I have included below the details of the previous publications arising from this project. Please contact me if you have any questions regarding the research or the interview. 
Thank you very much for considering this invitation. Please indicate your intention to participate (or otherwise) by return email

Dr Paul Genoni

School of Media, Culture and Creative Arts

Curtin University

\section{APPENDIX B: SURVEY INSTRUMENT}

Please respond to the following questions at the length you believe is necessary to provide a full answer. For each question where appropriate you are encouraged to explain the reason why you have given a particular response.

The term 'legacy print collections' as used in the questions refers to the collections of print items which are in very low circulation or demand but which may nonetheless retain some research value. The term includes both serial and non-serial publications.

Part A. The first four questions are intended to collect information relating to your library's storage of print materials.

1. Could you please outline the current medium-to-long term plans your library has (if any) for the storage of legacy print collections? Please refer as necessary to any distinctions that are made between serial and non-serial collections. Please also attach any relevant documents if these are publicly available.

2. What general factors or considerations are driving your library's planning with regard to the future storage of legacy print collections?

3. What data or information is, or would be, helpful to your decision making with regard to the retention, storage or disposal of legacy print collections?

4. Does your library have a preference for independent or joint/collaborative print storage? Please refer as necessary to the benefits or shortcomings of any current arrangements.

Part B. The following seven questions invite you to provide your personal views regarding the future storage of print collections and factors that might influence the storage of legacy print collections.

5. Do you believe academic libraries will require more or less on-site print storage space in the future? (In answering this question please feel free to refer to the circumstances of your own library).

6. Do you believe academic libraries will require more or less off-site print storage space in the future? (In answering this question please feel free to refer to the circumstances of your own library). 
7. In what way do you believe mass-digitisation programs (for example, Google Books) will impact upon future print storage requirements?

8. Do you believe it is necessary for Australia to be as independent as possible with regard to its research library needs?

9. How do you perceive the differences with regard to the academic library sector's obligations to the permanent retention of Australian publications as opposed to international publications?

10. To what extent do you believe cross-sectoral collaboration (for example, academic libraries collaborating with government and/or state libraries) is desirable and/or possible in meeting the needs for long term storage of legacy print collections?

11. Could you please indicate and discuss any other factors that you believe will be critical to the future storage of legacy print collections by Australian academic libraries?

Thank you very much. 